\title{
Succinct Approach to Delirium in the Emergency Department
}

\author{
Sangil Lee ${ }^{1}$ (D) $\cdot$ Clay Angel $^{2} \cdot$ Jin H. Han ${ }^{3,4}$ \\ Accepted: 3 March 2021 / Published online: 18 March 2021 \\ (C) The Author(s), under exclusive licence to Springer Science+Business Media, LLC, part of Springer Nature 2021
}

\begin{abstract}
Purpose of Review This study aims to provide a concise delirium review for practicing emergency medicine providers using the Assess, Diagnose, Evaluate, Prevent, and Treat (ADEPT) framework.

Recent Findings Delirium is a form of acute brain dysfunction that results in significant mortality and morbidity for older emergency department (ED) patients. Delirium is frequently missed by healthcare providers, but monitoring for this syndrome using brief delirium assessments may improve recognition. Once delirium is diagnosed, emergency medicine providers' primary goal is to perform a comprehensive history and physical examination to uncover the underlying etiology for delirium. This includes obtaining history from a collateral historian and obtaining an accurate medication history. If posssible, emergency physicians (EPs) should treat the medical etiology that precipitated the delirium. If agitated, non-pharmacologic interventions such that minimize the use of tethers are preferred. Pharmacologic agents such as antipsychotic medications should be used as a last resort.

Summary Delirium is a common geriatric emergency and requires the EP to assess, diagnose, evaluate, prevent, and treat. Delirium is a key geriatric syndrome that geriatric ED providers should routinely screen for. A strong emphasis is on the widespread use of delirium screening, followed by prevention and treatment efforts.
\end{abstract}

Keywords Delirium $\cdot$ Screening $\cdot$ Older adults $\cdot$ Agitation $\cdot$ Pharmacotherapy $\cdot$ Emergency department

\section{Introduction}

Delirium is defined as a disturbance in attention and awareness that is accompanied by an acute loss in cognition that cannot be better accounted for by a preexisting or evolving neurocognitive disorder such as dementia [1]. This form of acute brain dysfunction occurs in 10 to $17 \%$ of older ED patients [2, 3], 16 to $40 \%$ in older hospitalized patients

This article is part of the Topical collection on Neurologic Emergencies

Sangil Lee

kagocchi2@gmail.com

1 Department of Emergency Medicine, The University of Iowa Carver College of Medicine, Iowa City, IA, USA

2 Department of Hospital Medicine, Kaiser Permanente San Jose Medical Center, San Jose, CA, USA

3 Department of Emergency Medicine, Vanderbilt University Medical Center, Nashville, TN, USA

4 Geriatric Research, Education, and Clinical Center, Tennessee Valley Healthcare System, Nashville, TN, USA
[4-6], and up to $80 \%$ of intensive care unit (ICU) patients $[7,8]$.

The negative consequences of delirium are well established in the literature. Among older adults in the ED, delirium is associated with increased in-hospital and long-term mortality [2, 9-11], accelerated functional and cognitive decline [12], prolonged hospital stays $[12,13]$, intensive care unit (ICU) admissions [2,11], discharge to a skilled nursing facility [2], and increased rehospitalizations [2].

Despite the high morbidity and mortality associated with delirium, emergency healthcare providers miss this syndrome in approximately $75 \%$ of cases. Delirium is missed in 57 to $83 \%$ of the time when a patient has active delirium in the ED [4-10] because ED providers do not routinely screen for this [14]. The large body of evidence suggests that delirium is underrecognized in the ED. [15-19] If delirium is unrecognized in the ED, then the inpatient providers will also miss delirium $95 \%$ of cases [20].

Missing delirium likely has several negative implications for clinical care [21]. Because delirium is frequently misdiagnosed as dementia or psychiatric illnesses, such as depression [22], some may be inappropriately admitted to a psychiatric ward or discharged, thus delaying the diagnosis of 
their underlying medical illness [23]. If the patient is hospitalized, over $90 \%$ of delirium that is missed in the ED will also be missed in the hospital setting [20]. It is also possible that patients with active delirium are discharged after ED evaluation because EPs could not diagnose it or the condition was stabilized during their ED stay. Data suggests that $25 \%$ of delirious older ED patients are actually discharged and sent home $[13,17]$ and may not be able to fully comprehend their ED diagnosis or discharge instructions [24], leading to noncompliance and return ED visits and adverse outcomes [25].

Inadequate routine monitoring contributes to missed diagnosis of delirium. In the setting of credentialing to recognize the quality of practice such as geriatric ED accreditation and age-friendly health system, the needs of effective delirium screening, treatment, and prevention programs are urgently needed $[26,27 \bullet, 28 \bullet$. Using the Assess, Diagnose, Evaluate, Prevent, and Treat (ADEPT) framework by the American College of Emergency Physicians (ACEP) [29••], with additional insight from hospital medicine, we will describe a concise delirium review for practicing emergency medicine providers.

\section{Assessment}

The characteristics of delirium include acute onset, waxing and waning symptoms, inattention, change in cognition, or altered level of awareness [29••]. If a patient is delirious, the EP's primary goal is to determine the underlying etiology. First, life-threatening etiologies such as hypoxia, hypoglycemia, stroke, or acute myocardial infarction should be ruled out rapidly. Once these life-threatening conditions have been ruled out, a thorough history and physical examination should be performed to rule out other etiologies. Almost any medical illness can precipitate delirium. The most common etiology includes infection, intracranial lesions such as ischemic stroke, hemorrhage, or mass; electrolyte abnormalities; and medications. When considering delirium's underlying etiology, the EP should also evaluate the patient's vulnerability to developing delirium (Fig. 1). Patients with high vulnerability to developing delirium such as an 88-year-old with severe dementia who requires complete assistance to perform his/ her activities of daily living require a relatively benign insult such as an uncomplicated urinary tract infection to develop delirium. Patients with little vulnerability to developing delirium such as a fully functional 70-year-old who still works as an engineer will require a more noxious insult such as severe sepsis to develop delirium. In patients with little or no vulnerability to developing delirium, the EP should be highly concerned for an underlying life-threatening illness.

There are several key points to history taking for older adults with delirium or those who are at risk of developing delirium. Because delirious patients may not be able to provide an accurate history [24], it is vital that the history is confirmed by family, friends, or caregivers. Delirium can be precipitated by medication side effects or changes. Thus, it is imperative to obtain medication history, including over-thecounter medications, recent changes or altered compliance with medications, and missed medications. Medication lists obtained from the electronic medical record may not be accurate and should be confirmed. High-risk medications which include sedatives, corticosteroids, antihistamines, anticholinergics, tricyclic antidepressants, muscle relaxants, and opioids are notorious for precipitating delirium [34]. Furthermore, it is necessary to inquire about alcohol and illicit drug use.

When talking to a collateral historian, the EP should establish patients' baseline mental status and level of functioning [35]. Besides gaining insight into patient baseline and acute change, one may identify support services or resources for information and options for disposition. It helps to identify activities of daily living.

After history taking, EPs should perform a thorough physical exam, including vital signs. Point-of-care testing for glucose can identify reversible hypo- or hyperglycemia. A full examination of the patient is necessary to inspect the back, sacrum, genitalia, and feet for possible ulcers, infections, and drug patches. The neurological exam includes looking for signs of a stroke, intracranial hemorrhage, or subclinical seizures. This examination will provide an opportunity to evaluate for trauma, as well as accidental, self-inflicted, or nonaccidental injury. Besides routine exams, EPs may take a brief moment to assess for delirium by using the delirium assessment tools listed below.

\section{Diagnose}

Delirium is missed if its clinicians do not routinely screen for it. The Confusion Assessment Method (CAM) algorithm is the most widely researched and used delirium assessment. The short-form CAM consists of 4 features: (1) altered mental status or fluctuating course, (2) inattention, (3) disorganized thinking, and (4) altered level of consciousness [36]. A patient is considered to meet the criteria for delirium if both features 1 and 2 and either 3 or 4 are present. The CAM's features are determined by subjective impression after performing a brief global cognitive assessment. For this reason, the CAM requires extensive training, and its diagnostic accuracy is operator dependent. Several delirium assessments have incorporated brief objective assessments into the CAM algorithm. One example is the Brief Confusion Assessment Method (bCAM) which was designed for ED use. It asks the patient to recite the months of the year backwards from December to July to determine inattention and four yes/no questions and a simple command to determine disorganized thinking (Table 1). bCAM was reported to take less than 2 min but did not 
Fig. 1 Patient vulnerability factors for delirium. Footnote: Increased burden of these vulnerability factors will increase the patient's susceptibility to delirium. Modified from Han et al., Pun et al., Fearing et al., and the American Psychiatry Association Delirium Guidelines $[30,31,32,33 \bullet]$ * Psychoactive medications include benzodiazepines, opioids, and medications with anticholinergic properties.

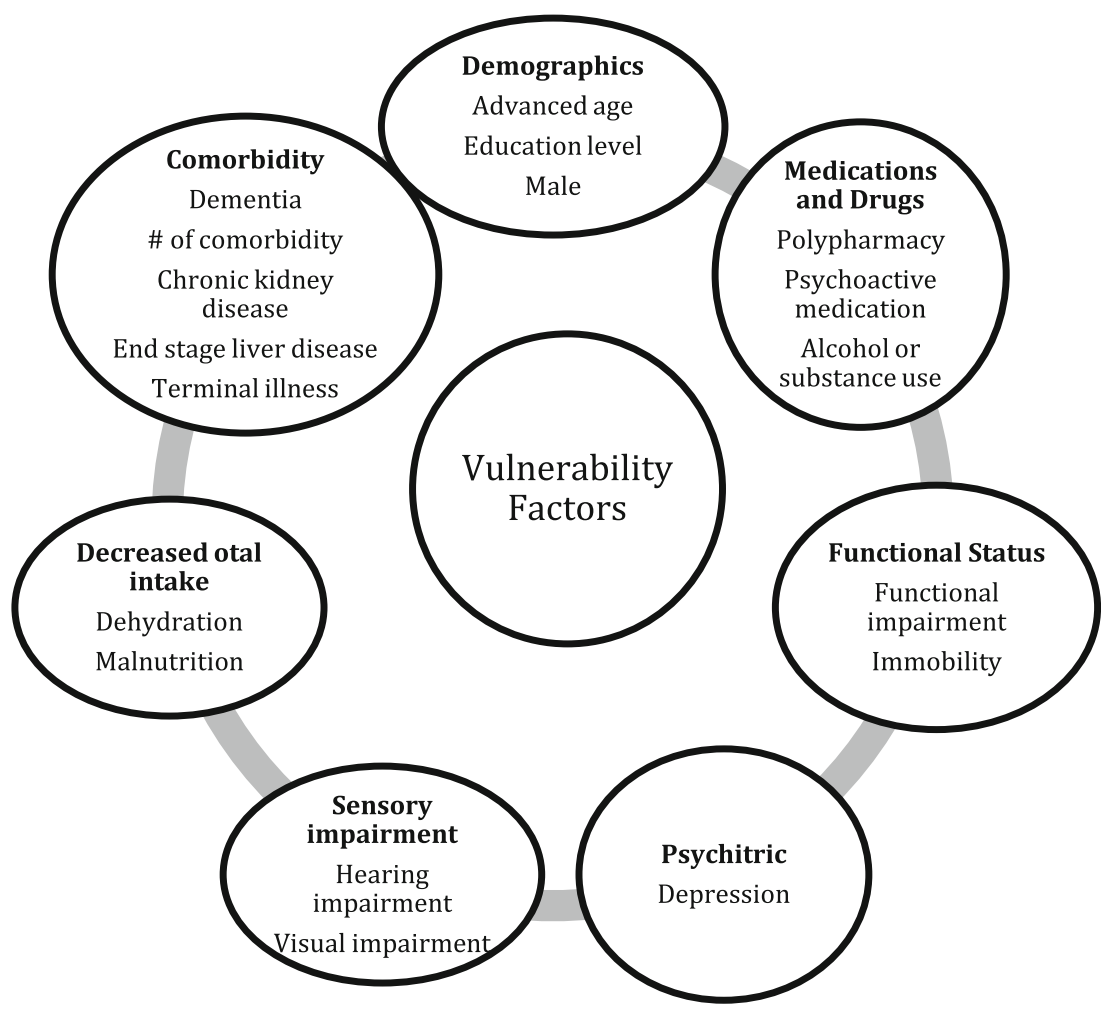

sacrifice sensitivity or specificity substantially, and there was a substantial inter-observer agreement (kapa 0.87) between EPs and research staff. [37]

The 4AT is another widely used delirium assessment and is comprised of four components: (1) alertness, (2) orientation, (3) attention, and (4) acute change or fluctuating course. The 4AT is similarly brief and also incorporates objective testing to determine inattention by asking the patient to recite the months backwards from December to July.

However, both the bCAM and 4AT can take 2 min to perform which may not be feasible for some EDs. To increase screening efficiency, a highly sensitive ultra-brief delirium assessment such as the Delirium Triage Screen (DTS) can be performed to rapidly rule out delirium. Because it has moderate specificity, a positive DTS, however, requires a confirmatory delirium assessment such as the bCAM or 4AT. Briefer delirium assessments typically come at the expense of diagnostic accuracy. However, the month of the years backwards task, Richmond Agitation Sedation Scale (RASS), or Single Question in Delirium (SQiD) can be viable alternative delirium assessments in the ED.

\section{Evaluate}

Once delirium is detected, the EP's primary role is to uncover the underlying etiology. The laboratory and radiographic evaluation should be guided by the history and physical examination. Table 2 lists the laboratory and radiographic tests that are commonly ordered.

It is important to note that the majority of patients with delirium will have more than one etiology. There are multifactorial etiologies contributing to delirium.

In older adults, delirium- and dementia-related psychoses are common causes of confusion and agitation. In this population, new-onset psychosis and schizophrenia are rare. Older adults with hallucinations, agitation, or altered sensorium usually experience delirium or dementia. Delirium has hyperactive, hypoactive, or mixed subtypes. Hyperactive delirium accompanies agitation and restlessness and is easier to recognize. Hypoactive delirium accompanies somnolence or decreased mental status. Mixed delirium has both features of hyperactive and hypoactive delirium. In the $\mathrm{ED}$, hypoactive delirium is the most common, has higher morality, and is missed more often [20].

\section{Prevention}

Finally, delirium prevention is a novel concept for EPs but has become a common language among hospitalists, geriatricians, and intensivists. The multiple and fast-paced decisions that must be made in the ED, coupled with an environment that is often unavoidably loud, bright, and intrusive, can be disorienting and frightening for older patients. Identifying the risk factors for delirium (such as infection, electrolytes, 
Table 1 Selected examples of delirium screening tools

\begin{tabular}{|c|c|c|c|c|}
\hline Instrument & Synopsis & Sensitivity & Specificity & Time \\
\hline Confusion Assessment Method (CAM) [38] & $\begin{array}{l}\text { A bedside cognitive test is used to determine (1) altered mental } \\
\text { status or fluctuating course, (2) inattention, (3) disorganized } \\
\text { thinking, and (4) altered level of consciousness using clinical } \\
\text { impression }\end{array}$ & $86 \%$ & $93 \%$ & $5-10 \mathrm{~min}$ \\
\hline $\begin{array}{l}\text { Brief Confusion Assessment Method } \\
\text { (bCAM) [37] }\end{array}$ & $\begin{array}{l}\text { Uses the CAM algorithm but uses objective testing to evaluate } \\
\text { inattention and disorganized thinking }\end{array}$ & $84 \%$ & $96 \%$ & $<2 \min$ \\
\hline 4AT [39] & Evaluates alertness, orientation, attention, and fluctuation & $88 \%$ & $88 \%$ & $<2 \min$ \\
\hline Delirium Triage Screen (DTS) [37] & $\begin{array}{l}\text { Evaluates inattention using object testing and level of } \\
\text { consciousness using DTS followed by more specific test to } \\
\text { confirm }\end{array}$ & $98 \%$ & $55 \%$ & $<30 \mathrm{sec}$ \\
\hline $\begin{array}{l}\text { Month of the year backwards }-12 \text { months } \\
\text { (MOTYB-12) [40•] }\end{array}$ & $\begin{array}{l}\text { Asks the patient to recite the months of the year backwards from } \\
\text { December to July }\end{array}$ & $84 \%$ & $71 \%$ & $<1 \min$ \\
\hline Richmond Agitation Sedation Scale [41] & $\begin{array}{l}\text { A structured evaluation of level of consciousness based on your } \\
\text { observation of the patient during routine clinical evaluation }\end{array}$ & $82 \%$ & $85 \%$ & $<10 \mathrm{sec}$ \\
\hline Single Question in Delirium (SQiD) & "Do you think [name of patient] has been more confused lately?" & $80 \%$ & $71 \%$ & $<30 \mathrm{sec}$ \\
\hline
\end{tabular}

dehydration, or high-risk medication) can have preventive effects. Although the use of tethers (Foley catheters, telemetry, and intravenous lines [IVs]) is often essential in providing care, it adds yet another layer of complexity that can lead to agitation and delirium. The goal of care to maintain function should be a focus, and this can include active hydration, limiting NPO time, access to food and toileting, and visual/ hearing assists. Sleep regulation and minimizing disruption by turning off the light at night is feasible in the ED. Although pharmacological interventions are sometimes necessary in the treatment of our fragile older patients, there are therapeutic choices and doses that are safer and often equally effective.

Table 2 General tests for delirium in the ED

\begin{tabular}{|c|c|c|}
\hline Name of test & Remarks & Identifiable etiology \\
\hline Point-of-care glucose & \multirow[t]{3}{*}{ Finger stick } & Hypo- and hyperglycemia \\
\hline Complete blood count & & Anemia, leukocytosis \\
\hline $\begin{array}{l}\text { Basic or comprehensive metabolic } \\
\text { panel }\end{array}$ & & $\begin{array}{l}\text { Hypo-/hypernatremia, hyperkalemia, } \\
\text { hypercalcemia, uremia, } \\
\text { acute kidney injury, dehydration }\end{array}$ \\
\hline Comprehensive metabolic panel & $\begin{array}{l}\text { May also consider comprehensive metabolic panel, liver } \\
\text { function panel, ammonia, venous blood gas }\end{array}$ & $\begin{array}{l}\text { Liver disease (cirrhosis, hepatitis, hepatic } \\
\text { encephalopathy), drug, medication } \\
\text { complication, or side effect }\end{array}$ \\
\hline Urinalysis and urine culture & $\begin{array}{l}\text { High rates of asymptomatic pyuria and bacteriuria in older } \\
\text { adults. Consider alternative etiologies especially in the } \\
\text { absence of symptoms of UTI or pyelonephritis, signs of } \\
\text { infection such as fever or leukocytosis }\end{array}$ & Urinary tract infection \\
\hline Electrocardiogram & May also add BNP, troponin, and CXR. & $\begin{array}{l}\text { Ischemic changes, arrhythmia, electrolyte } \\
\text { abnormality }\end{array}$ \\
\hline Chest X-ray & May expand infection workup and imaging & Infection \\
\hline $\begin{array}{l}\text { Drug levels (lithium, digoxin, } \\
\text { acetaminophen, salicylate, ethanol } \\
\text { level, urine drug screen) }\end{array}$ & Venous blood gas could supplement the evaluation of drugs & $\begin{array}{l}\text { Drug and medication complications } \\
\text { Alcohol withdrawal }\end{array}$ \\
\hline Head CT & & $\begin{array}{l}\text { Trauma, Subarachnoid hemorrhage, } \\
\text { hemorrhagic stroke }\end{array}$ \\
\hline \multicolumn{3}{|l|}{ Miscellaneous } \\
\hline Venous blood gas, & & $\mathrm{CO} 2$ retention \\
\hline Thyroid-stimulating hormone & & Hypo-/hyperthyroidism \\
\hline Carboxyhemoglobin & & $\mathrm{CO}$ poisoning \\
\hline $\begin{array}{l}\text { Blood culture } \\
\text { Lactic acid } \\
\text { Lumbar puncture }\end{array}$ & Selective indication for infection & Infection \\
\hline
\end{tabular}


Polypharmacy is a real problem in our hospitals, and "less is more" applies to both the frequency with which we prescribe medications and the dosage and frequency.

Preventing delirium might require hospital and systembased measures. Increased length of stay in the ED is generally associated with worse outcomes, and recent studies report an increased risk of delirium $[42,43 \bullet]$. Since delirious patients are at risk of falls, environmental modification programs such as lowering beds, providing chairs, and nonslip floors or footwear are recommended. Delirium programs recommend not using hallway beds for those who are at risk for delirium and plan expeditious transfer to the designated unit [44•, 45]. If sufficient resources are available, a sitter can monitor patients who are at high risk of falls and agitation.

\section{Treat}

EPs will need to consider a multimodal approach to treat delirium in the ED. First, treat the underlying medical condition or derangements based on the evaluation that should be addressed. This means to treat symptoms such as pain, fever, and nausea or initiating antimicrobial therapy for a bacterial infection. Beyond this, the active management of delirium requires consideration of both non-pharmacological and pharmacological options.

The treatment of delirium can start with a nonpharmacological modality. There is a need to mobilize resources, including ancillary staff, when the patients are at high risk for delirium or have active delirium. First, many ED patients are kept nothing by mouth (NPO) for an anticipatory procedure. NPO status should be reassessed, and EPs should address hydration, avoid unnecessary NPO order, and consider feeding assistance [46-48]. Since the decreased activity level is associated with delirium [20], a mobility assessment and a trial of ambulation are a part of geriatric assessments [49]. Often time, assisted ambulation with a nursing assistant or volunteer will suffice. When prolonged immobilization is anticipated, or ambulatory status is difficult to assess, consider using physical therapy. Timed Up \& Go (TUG) test is recommended for mobility assessment and can be implemented without access to physical therapy in the ambulatory setting. TUG test has the following steps. (1) Patients wear their regular footwear and can use a walking aid, if needed. (2) The patient starts in a seated position. (3) The patient stands up upon the therapist's command: walks $3 \mathrm{~m}$, turns around, walks back to the chair, and sits down. (4) The time stops when the patient is seated. (5) Be sure to document the assistive device used. Since inadequate sleep is associated with delirium, minimize disruption for lab draws, alarms, and noise at nighttime when possible. Also, EPs should sparingly use tethers such as IVs, monitoring, and Foley catheter [50•]. In addition to limiting mobility, ethers can lead to or worsen agitation.

If the older ED patient becomes agitated while delirious, EPs should assess safety risk for both the patients and staff. If at all possible, non-pharmacological measures to reduce agitation should be performed. This verbal de-escalation techniques (Table 3 ), turning of the lights and minimizing ambient noise, provide reassurance and redirection and provide a means for self-orientation by using clocks, calendars, and signs. Some disoriented patients may become more agitated when their perception of reality is challenged. You may encourage family members or caregivers who demonstrate a calming presence to remain at their bedside. Agitation may be secondary to discomfort, and older patients with delirium or dementia may have difficulty verbalizing this. It is important to rule out urinary retention, constipation, or pain as the cause of their agitation. For the agitated older ED patient, EPs will need to evaluate falls risk and place precautions as needed. Such patients may require a one-toone sitter to prevent injury during their ED stay.

Pharmacological options are reserved for agitation with delirium. Non-pharmacological options should be tried first $[51 \bullet \bullet$. There are no FDA-approved medications for the treatment of delirium; however, antipsychotics are commonly used to manage hyperactive or psychotic symptoms that threaten safety when non-pharmacologic approaches are ineffective. If pharmacological options are needed, one should start with oral medications. When medications are needed, one should start with low doses and titrate. Rather than choosing a new agent, we recommend the use of antipsychotics previously given at home. If a patient demonstrates a risk of harm to others due to agitation, one may use the list of medications below (Table 4) [29••]. If necessary, one may consider the use of IM or IV medications. This is indicated when oral medication is not effective. Starting the lowest effective dose to maintain patient and staff safety and redosing may be needed.

Black box warning: Antipsychotic agents have a black box warning that they increase the risk of death in older adults with
Table 3 The principles of verbal de-escalation

\begin{tabular}{ll}
\hline - Respect personal space & $\bullet$ Listen closely to what the patient is saying \\
\hline - Do not be provocative & - Agree or agree to disagree \\
- Establish verbal contact & $\bullet$ Set clear limits \\
- Be concise and use simple language & $\cdot$ Other choices and optimism \\
- Identify the patient's wants and feelings & $\bullet$ Debrief the patient and staff
\end{tabular}


Table 4 Pharmacological therapy

\begin{tabular}{|c|c|c|}
\hline Oral agent & Dose & Contraindications and risks \\
\hline Risperidone & $\leq 1 \mathrm{mg} \mathrm{PO}$ & $\begin{array}{l}\text { Orthostatic hypotension } \\
\text { Caution for frail or hypovolemic patient }\end{array}$ \\
\hline Olanzapine & $2.5-5 \mathrm{mg}$ PO & Orthostatic hypotension and somnolence \\
\hline Quetiapine & $25-50 \mathrm{mg}$ PO & Orthostatic hypotension and somnolence \\
\hline IM or IV dose & Dose & Contraindications and risks \\
\hline Olanzapine & $2.5-5 \mathrm{mg} \mathrm{IM} / \mathrm{IV}$ & Caution in intoxicated or hypovolemic patients \\
\hline Ziprasidone & $10 \mathrm{mg} \mathrm{IM}$ & Caution in uncontrolled heart failure or cardiac disease, intoxicated, or hypovolemic/orthostatic patients \\
\hline Haloperidol & $\begin{array}{l}1-2.5 \mathrm{mg} \text { IM } \\
0.25-1 \mathrm{mg} \mathrm{IV}\end{array}$ & $\begin{array}{l}\text { More extrapyramidal side effects than the atypical antipsychotics } \\
\text { IM is preferred to IV. IV may precipitate torsade de pointes in patients with QT prolongation. }\end{array}$ \\
\hline
\end{tabular}

dementia, but the exact mechanism for increased mortality is unknown [52・*].

Besides considerations to pharmacological agents to control agitation, it is also necessary to review and identify medications related to harm. Several medications are associated with delirium and increased agitations. Many are listed in the Beers criteria [34], and some examples include diphenhydramine for agitation in older adults. Diphenhydramine has anticholinergic side effects and produces prolonged sedation. Long-term exposure is known to increase the risk of delirium.

Benzodiazepines are commonly used in ED and inpatient treatment, but the risk of delirium is reported in the previous literature. The use of benzodiazepines in older adults is associated with an increased risk of sedation, agitation, and worsened delirium [53•]. There are specific indications where benzodiazepines are the first choice, which are alcohol withdrawal, substance-induced delirium, and chronic benzodiazepine use. It is recommended that a low dose of a benzodiazepine, such as lorazepam, is started from 0.5 to $1 \mathrm{mg}$ either PO, IM, or IV $[29 \cdot \bullet]$.

A common EM practice involves the assessment and treatment of pain with various analgesias. Studies suggest that pain is associated with delirium [54], and the use of opioids is associated with delirium $[55,56]$. Since evidence is still conflicting, this decision is best determined by the clinicians at the bedside. For physicians to avoid heavy reliance on opioid pain medication amid the opioid pandemic, it is recommended to use a multimodal pain management plan. There is an emerging evidence to use regional anesthesia for fracture care instead of systemic opioid, and when resource and skillset are available, it can be an effective modality in the ED. [57-60]

\section{Transition of Care to Hospital Medicine}

The frail older adults with concomitant cognitive impairment are a challenging subset who often require hospitalization. Treatments started in the ED can easily have a lasting and significant effect on hospital courses, outcomes, and length of stay. When care is transferred to another physician, the focus of care shifts to the management of multiple, active, and on-going diseases processes that will, on average, take 3 to 4 days to resolve depending on the subsequent level of disposition (home, home with home health, SNF, hospice, etc.).

When these patients are admitted to the inpatient setting, it is important that our ED and hospital medicine colleagues speak the same language, especially with regard to evaluating mentation. If your inpatient setting has a successful delirium program, it is important to follow its lead regarding assessment and choose a similar tool that will translate from the ED to the inpatient level of care. Mentation assessments should be considered as a vital sign. As delirium awareness and education continue to increase across the country, so do the number of inpatients, ED, and ICU delirium management programs. As delirium awareness and education continue to increase across the country, so do the number of inpatient, ED, and ICU delirium management programs. To develop a common ground, we recommend the use of the ADEPT tool to build a program.

\section{Conclusion}

Delirium is a common geriatric emergency and requires the EP to assess, diagnose, evaluate the severity and its etiology, prevent, and treat the underlying cause. The management and prevention of delirium is an area of active investigation. Delirium is a key geriatric syndrome that geriatric ED providers should routinely screen for. A strong emphasis is on the widespread use of delirium screening followed by prevention and treatment efforts.

Acknowledgement This review followed the ADEPT tool which was developed by the American College of Emergency Physicians (ACEP).

Funding Dr. Lee was supported by the NIDUS delirium network (No. NIA R24AG054259), and Health Resources and Service Administration (HRSA)2U1QHP287310400. Dr. Han was supported by the National 
Institutes of Health (NIH) under the award number R21AG06312, R56HL141567, and R01AG065249. Dr. Han is also supported by the Veteran Affairs Geriatric Research, Education, and Clinical Center (GRECC).

\section{References}

Papers of particular interest, published recently, have been highlighted as:

- Of importance

•- Of major importance

1. American Psychiatric Association., American Psychiatric Association. DSM-5 Task Force. Diagnostic and statistical manual of mental disorders : DSM-5. 5th ed. Washington, D.C.: American Psychiatric Association; 2013.

2. Kennedy M, Enander RA, Tadiri SP, Wolfe RE, Shapiro NI, Marcantonio ER. Delirium risk prediction, healthcare use and mortality of elderly adults in the emergency department. J Am Geriatr Soc. 2014;62(3):462-9.

3. Han JH, Shintani A, Eden S, Morandi A, Solberg LM, Schnelle J, et al. Delirium in the emergency department: an independent predictor of death within 6 months. Ann Emerg Med. 2010;56(3):244 52.

4. Francis J, Martin D, Kapoor WN. A prospective study of delirium in hospitalized elderly. JAMA. 1990;263(8):1097-101.

5. O'Keeffe S, Lavan J. The prognostic significance of delirium in older hospital patients. J Am Geriatr Soc. 1997;45(2):174-8.

6. Ely EW, Gautam S, Margolin R, Francis J, May L, Speroff T, et al. The impact of delirium in the intensive care unit on hospital length of stay. Intensive Care Med. 2001;27(12):1892-900.

7. McNicoll L, Pisani MA, Zhang Y, Ely EW, Siegel MD, Inouye SK. Delirium in the intensive care unit: occurrence and clinical course in older patients. J Am Geriatr Soc. 2003;51(5):591-8.

8. Adams Wilson JR, Morandi A, Girard TD, Thompson JL, Boomershine CS, Shintani AK, et al. The association of the kynurenine pathway of tryptophan metabolism with acute brain dysfunction during critical illness*. Crit Care Med. 2012;40(3): 835-41.

9. Kakuma R, du Fort GG, Arsenault L, Perrault A, Platt RW, Monette $\mathrm{J}$, et al. Delirium in older emergency department patients discharged home: effect on survival. J Am Geriatr Soc. 2003;51(4):443-50.

10. Han JH, Shintani A, Eden S, Morandi A, Solberg LM, Schnelle J, et al. Delirium in the emergency department: an independent predictor of death within 6 months. Ann Emerg Med. 2010;56(3):244 $52 \mathrm{e} 241$.

11. Hsieh SJ, Madahar P, Hope AA, Zapata J, Gong MN. Clinical deterioration in older adults with delirium during early hospitalisation: a prospective cohort study. BMJ Open. 2015;5(9): e007496.

12. Han JH, Vasilevskis EE, Chandrasekhar R, Liu X, Schnelle JF, Dittus RS, et al. Delirium in the emergency department and its extension into hospitalization (DELINEATE) study: effect on 6month function and cognition. J Am Geriatr Soc. 2017;65(6): 1333-8.

13. Han JH, Eden S, Shintani A, Morandi A, Schnelle J, Dittus RS, et al. Delirium in older emergency department patients is an independent predictor of hospital length of stay. Acad Emerg Med. 2011;18(5):451-7.

14. Press Y, Margulin T, Grinshpun Y, Kagan E, Snir Y, Berzak A, et al. The diagnosis of delirium among elderly patients presenting to the emergency department of an acute hospital. Arch Gerontol Geriatr. 2009;48(2):201-4

15. Elie M, Rousseau F, Cole M, Primeau F, McCusker J, Bellavance F. Prevalence and detection of delirium in elderly emergency department patients. CMAJ. 2000;163(8):977-81.

16. Hustey FM, Meldon SW. The prevalence and documentation of impaired mental status in elderly emergency department patients. Ann Emerg Med. 2002;39(3):248-53.

17. Hustey FM, Meldon SW, Smith MD, Lex CK. The effect of mental status screening on the care of elderly emergency department patients. Ann Emerg Med. 2003;41(5):678-84.

18. Lewis LM, Miller DK, Morley JE, Nork MJ, Lasater LC, Unrecognized delirium in ED geriatric patients. Am J Emerg Med. 1995;13(2):142-5.

19. Suffoletto B, Miller T, Frisch A, Callaway C. Emergency physician recognition of delirium. Postgrad Med J. 2013;89(1057):621-5.

20. Han JH, Zimmerman EE, Cutler N, Schnelle J, Morandi A, Dittus RS, et al. Delirium in older emergency department patients: recognition, risk factors, and psychomotor subtypes. Acad Emerg Med. 2009;16(3):193-200.

21. Sanders AB. Missed delirium in older emergency department patients: a quality-of-care problem. Ann Emerg Med. 2002;39(3): 338-41.

22. Farrell KR, Ganzini L. Misdiagnosing delirium as depression in medically ill elderly patients. Arch Intern Med. 1995;155:2459-64.

23. Reeves RR, Parker JD, Burke RS, Hart RH. Inappropriate psychiatric admission of elderly patients with unrecognized delirium. South Med J. 2010;103(2):111-5.

24. Han JH, Bryce SN, Ely EW, Kripalani S, Morandi A, Shintani A, et al. The effect of cognitive impairment on the accuracy of the presenting complaint and discharge instruction comprehension in older emergency department patients. Ann Emerg Med. 2011;57(6):662-71 e662.

25. Clarke C, Friedman SM, Shi K, Arenovich T, Monzon J, Culligan C. Emergency department discharge instructions comprehension and compliance study. CJEM. 2005;7(1):5-11.

26. Carpenter CR, Melady D, Krausz C, Wagner J, Froelke B, Cordia J, et al. Improving emergency department care for aging Missourians: guidelines, accreditation, and collaboration. Mo Med. 2017;114(6): 447-52.

27. Fulmer T. Age-friendly health systems transform care for older adults. Modern Healthcare. Retrieved July 2, 2019. Available at :www.johnahartford.org/images/uploads/resources/ MonderHealthcareExecutiveInsight TF 2.11.19.pdf. Accessed April 20, 2019. This article described the resource available for an age-friendly health system.

28. De Biasi A, Wolfe M, Carmody J, Fulmer T, Auerbach J. Creating an age-friendly public health system. Innov Aging. 2020, 4(1): igz044 This article described the concept of an age-friendly health system and $\mathbf{4 M s}$ framework.

29.• Shenvi C, Kennedy M, Austin CA, Wilson MP, Gerardi M, Schneider S. Managing delirium and agitation in the older emergency department patient: the ADEPT tool. Ann Emerg Med. 2019; This article described the concept and details of the ADEPT tool.

30. Pun BT, Ely EW. The importance of diagnosing and managing ICU delirium. Chest. 2007;132(2):624-36.

31. Practice guideline for the treatment of patients with delirium. American Psychiatric Association. Am J Psychiatry 1999 May;156(5 Suppl):1-20.

32. Fearing MA, Inouye SK. Delirium. In: Blazer DG, Steffens DC, editors. The American Psychiatric Publishing Textbook of Geriatric Psychiatry, vol. 7. 4th ed. Washington, D. C.: American Psychiatric Publishing; 2009. p. 53-63. 
33. Han JH, Suyama J. Delirium and Dementia. Clin Geriatr Med. 2018;34(3):327-54 This is a comprehensive review of delirium and dementia targeted for clinicians.

34. Steinman MA, Beizer JL, DuBeau CE, Laird RD, Lundebjerg NE, Mulhausen P. How to use the American Geriatrics Society 2015 Beers Criteria - a guide for patients, clinicians, health systems, and payors. J Am Geriatr Soc. 2015;63(12):e1-7.

35. McCleary E, Cumming P. Improving early recognition of delirium using SQiD (single question to identify delirium): a hospital based quality improvement project. BMJ Qual Improv Rep. 2015;4(1).

36. Inouye SK, van Dyck CH, Alessi CA, Balkin S, Siegal AP, Horwitz RI. Clarifying confusion: the confusion assessment method. A new method for detection of delirium. Ann Intern Med. 1990;113(12): 941-8.

37. Han JH, Wilson A, Vasilevskis EE, Shintani A, Schnelle JF, Dittus RS, et al. Diagnosing delirium in older emergency department patients: validity and reliability of the delirium triage screen and the brief confusion assessment method. Ann Emerg Med. 2013;62(5): 457-65.

38. Wong CL, Holroyd-Leduc J, Simel DL, Straus SE. Does this patient have delirium?: value of bedside instruments. JAMA. 2010;304(7):779-86.

39. Bellelli G, Morandi A, Davis DH, et al. Validation of the 4AT, a new instrument for rapid delirium screening: a study in 234 hospitalised older people. Age Ageing. 2014;43(4):496-502.

40. Marra A, Jackson JC, Ely EW, et al. Focusing on Inattention: the diagnostic accuracy of brief measures of inattention for detecting delirium. J Hosp Med. 2018;13(8):551-7 This is a prospective study that assessed the diagnostic utility of the month of year backward test, concluding the limitation of focusing on the inattention to diagnose delirium.

41. Han JH, Vasilevskis EE, Schnelle JF, Shintani A, Dittus RS, Wilson A, et al. The diagnostic performance of the Richmond agitation sedation scale for detecting delirium in older emergency department patients. Acad Emerg Med. 2015;22(7):878-82.

42. Emond M, Grenier D, Morin J, et al. Emergency department stay associated delirium in older patients. Canadian Geriatr J : CGJ. 2017;20(1):10-4.

43. Emond M, Boucher V, Carmichael PH, et al. Incidence of delirium in the Canadian emergency department and its consequences on hospital length of stay: a prospective observational multicentre cohort study. BMJ Open. 2018;8(3):e018190 This study showed an increased ED length of stay and risk of delirium in Canadian EDs.

44. Barnes-Daly MA, Pun BT, Harmon LA, et al. Improving health care for critically ill patients using an evidence-based collaborative approach to ABCDEF bundle dissemination and implementation. Worldviews Evid Based Nurs. 2018;15(3):206-16 This study addressed the implementation of the ABCDEF bundle in the ICU setting.

45. Inouye SK, Bogardus ST Jr, Baker DI, Leo-Summers L, Cooney LM Jr. The Hospital Elder Life Program: a model of care to prevent cognitive and functional decline in older hospitalized patients. Hospital Elder Life Program. J Am Geriatr Soc. 2000;48(12): 1697-706.

46. Franklin GA, McClave SA, Hurt RT, et al. Physician-delivered malnutrition: why do patients receive nothing by mouth or a clear liquid diet in a university hospital setting? JPEN J Parenter Enteral Nutr. 2011;35(3):337-42.

47. Sorita A, Thongprayoon C, Ahmed A, Bates RE, Ratelle JT, Rieck $\mathrm{KM}$, et al. Frequency and appropriateness of fasting orders in the hospital. Mayo Clin Proc. 2015;90(9):1225-32.
48. Denton TD. Southern Hospitality: How we changed the NPO practice in the emergency department. J Emerg Nurs. 2015;41(4):31722.

49. Carpenter CR, Bromley M, Caterino JM, Chun A, Gerson LW, Greenspan J, et al. Optimal older adult emergency care: introducing multidisciplinary geriatric emergency department guidelines from the American College of Emergency Physicians, American Geriatrics Society, Emergency Nurses Association, and Society for Academic Emergency Medicine. Ann Emerg Med. 2014;63(5):e1-3.

50. Bo M, Porrino P, Di Santo SG, et al. The association of indwelling urinary catheter with delirium in hospitalized patients and nursing home residents: an explorative analysis from the "Delirium Day 2015". Aging Clin Exp Res. 2019;31(3):411-20 This study showed an increased risk of delirium with indwelling urinary catheters among nursing home patients who required hospitalization.

51.• Devlin JW, Skrobik Y, Gelinas C, et al. Clinical practice guidelines for the prevention and management of pain, agitation/sedation, delirium, immobility, and sleep disruption in adult patients in the ICU. Crit Care Med. 2018;46(9):e825-73 This guideline described the evidence-based recommendation related to drugs from ICU specialty.

52.• Ralph SJ, Espinet AJ. Increased all-cause mortality by antipsychotic drugs: updated review and meta-analysis in dementia and general mental health care. J Alzheimers Dis Rep. 2018;2(1):1-26 This is the first meta-analysis to include evidence from the general mental health studies showing that antipsychotic drugs precipitate excessive mortality across the spectrum.

53. Pandharipande P, Shintani A, Peterson J, et al. Lorazepam is an independent risk factor for transitioning to delirium in intensive care unit patients. Anesthesiology. 2006;104(1):21-6 This prospective cohort study showed that there is an association between pain at rest and delirium, suggesting pain may be a risk factor for delirium.

54. Feast AR, White N, Lord K, Kupeli N, Vickerstaff V, Sampson EL. Pain and delirium in people with dementia in the acute general hospital setting. Age Ageing. 2018;47(6):841-6.

55. Swart LM, van der Zanden V, Spies PE, de Rooij SE, van Munster BC. The comparative risk of delirium with different opioids: a systematic review. Drugs Aging. 2017;34(6):437-43.

56. Schor JD, Levkoff SE, Lipsitz LA, Reilly CH, Cleary PD, Rowe JW, et al. Risk factors for delirium in hospitalized elderly. JAMA. 1992;267(6):827-31.

57. Riddell M, Ospina M, Holroyd-Leduc JM. Use of femoral nerve blocks to manage hip fracture pain among older adults in the emergency department: a systematic review. CJEM. 2016;18(4):245-52.

58. Fletcher AK, Rigby AS, Heyes FL. Three-in-one femoral nerve block as analgesia for fractured neck of femur in the emergency department: a randomized, controlled trial. Ann Emerg Med. 2003;41(2):227-33.

59. Morrison RS, Dickman E, Hwang U, Akhtar S, Ferguson T, Huang $\mathrm{J}$, et al. Regional nerve blocks improve pain and functional outcomes in hip fracture: a randomized controlled trial. J Am Geriatr Soc. 2016;64(12):2433-9.

60. Sharma S, Iorio R, Specht LM, Davies-Lepie S, Healy WL. Complications of femoral nerve block for total knee arthroplasty. Clin Orthop Relat Res. 2010;468(1):135-40.

Publisher's Note Springer Nature remains neutral with regard to jurisdictional claims in published maps and institutional affiliations. 